\title{
Optimum Extraction of Micro Grid, Using the Load Transmission from the Demand Side Management Program
}

\author{
Soheil Abbasi ${ }^{1}$, Abbas Saberi Noughabi ${ }^{2}$ \\ ${ }^{I}$ Department of electrical engineering, Azad university branch of Gonabad \\ ${ }^{2}$ Department of electrical engineering Assistant professor, University of Birjand
}

\begin{abstract}
One of the important problems in optimum extraction of power system, is the micro grid optimum extraction, considering the demand side management. Demand Side Management performance reduces the extraction cost of power system and on the other hand these kind of programs need the financial encouraging policies. In this paper, the optimum extraction problem from micro grids has been formulated in addition to demand side management.

Load transmission has been considered as an effective solution in demand side management. Objective function of this problem is the reduction of extraction costs, the problem criteria contain the extraction criteria and performance limitations for the load transmission. In this problem, the amount of load transmission per hour has been considered as the problem variables and for this problem, the Genetic Algorithm and optimum load distribution algorithm have been used in combination to each other. The suggested method performed on a sample micro grid and results showed that with demand side management it is possible to reduce the micro grid total extraction costs.
\end{abstract}

Keywords: optimum extraction, Demand Side Management, micro grid, hybrid algorithm

\section{Introduction}

Nowadays the power system extractors are faced to problems such as considerable load changes, rapid growth of demands, and geographic distribution of clients. On the other hand investors wouldn't like the foundation of fossil fuel power plants because of the reduction in fossil fuel resources, low energy efficiency and environmental policies. Therefore aforementioned challenges increased the declination of power production in distributed voltage level. So the solution is the independent small network manufacturing or micro grids.

Shokravi and Parsa Moghaddam (1392) evaluated the extraction of micro grid appointed with renewable and power saving resources. Liao and Tsai (2014) used the intelligent micro grid and showed that utilizing the intelligent micro grid not only increases the energy efficiency but also can be used as a complement grid for the modifying of reliability and quality. Also Liu et al (2012), showed that using of suitable power saving devices, the active power fluctuations can be fixed and keep the micro grid frequency at given amount. Jayadev and Swarap (2013) used the economic programming for the load production. Toma and Bica (2013) expressed a market strategy for this challenge. Therefor in this article, the optimized extraction of micro grids along with demand side management have been formulated, improving the general methods in power system extraction and considering the reasonable criteria. The objective function is minimizing the extraction and demand side management costs and the problem criteria are the generators limitation and the power balance. Also the load transmission amount per hour, has been considered as the problem variable. The Genetic algorithm and optimum load distribution have been utilized in this article, solving the optimization problem.

\section{Demand Side Management}

It generally predicated to the programs effect the client's power consumption pattern. In other word they are some programs that designed for changing in amount and time of power consumption as provide the benefits for both consumers and producers.

It consists of two main section:

A. Optimize energy efficiency: the aim of these programs is the permanent reduction of energy consumption, generally is provided via technology and final consumer devices changing.

B. Load responsibility: it is a novel change in demand side management domain, means the consumer partnership in modifying the energy consumption pattern. Indeed this partnership occurs in response of moment price oscillations (Keyhani and Marwali, 2011; Hu et al, 2013).

\section{The Problem Formulation}

The unit's production programming is the optimization problems, will be formulated and consists of below sections: 
- $\quad$ minimizing the total extraction costs during the programming period along with demand side management performance costs.

- $\quad$ minimizing the costs of demand side management programs usage for decreasing the customer displeasure (Ebrahimi Bojdani and Shabaani Dehbone, 1393; Toma and Bica, 2013)

The problem objective function is expressed in mathematical form as below:

$$
\operatorname{Min} F=\{C F, D C\}
$$

Where the $\mathrm{F}$ is the total extraction costs, $\mathrm{CF}$ is the sum of power producing unit's extraction cost and DC is the sum of demand side management program performance costs. In this article the load replacement program has been utilized. This program performing caused the customer's displeasure that can be modelled as a function like relation 2 .

$$
D C=\left[A_{l} s t_{l}^{3}+B_{l} s t_{l}^{2}+C_{l} s t_{l}\right]
$$

Where 1 is the load type, A, B and C are the coefficients for each load type and st is the number of load replacement duration. The extraction costs consist of unit's production, performance, maintains and repair costs. Also the sale and buy costs have been included in cost function. Relation 3 shows the CF cost function in production unit's programming.

$$
C F=\sum_{t=1}^{T} \sum_{i=1}^{I}[C(i, t)+S C(i, t)+M C(i, t)]+\sum_{t=1}^{T}[C(t)-R(t)]
$$

Where $\mathrm{C}(\mathrm{i}, \mathrm{t})$ is the cost of $\mathrm{i}^{\text {th }}$ unit production at $\mathrm{t}$ hour extraction, $\mathrm{MC}$ (i.t) is the cost of maintains and repair of equipment and finally SC (i.t) is the cost of implementation of $i^{\text {th }}$ at $t$ hour. Also $C(t)$ is the cost of purchased power from the main network, $R(t)$ is the daily earn of sold power to main network. I is the number of power producing units and $\mathrm{T}$ is the study duration equal to 24 hour. The purchased and sold power cost has been expressed in relations 4 and 5 respectively.

$$
\begin{aligned}
& C(t)=T_{p p} \times P_{p p} \\
& R(t)=T_{s p} \times P_{s p}
\end{aligned}
$$

Where $T_{p p}$ is the power purchase tariff and $P_{p p}$ is the bought power from network, Tsp is the power sale tariff to the network and Psp is the sold power to network. Maintains and repair cost of unit $\mathrm{i}^{\text {th }}$ at hour $\mathrm{t}$ expressed as below:

$$
M C(i, t)=P(i, t) \times K(i)
$$

Where K (i) is the cost of unit $\mathrm{i}^{\text {th }}$ per each Kilo Watt and P (I, t) is the produced power of unit $\mathrm{i}^{\text {th }}$ at hour $\mathrm{t}^{\text {th }}$. The implementation cost only considered for fuel consumer production units. The implementation cost only belongs to the units evert time that is turned on. Below equations show the implementation cost of unit $i^{\text {th }}$ at hour $\mathrm{t}^{\text {th }}$.

$$
S C(i, t)=S \cos t(i) \times(u(i, t)-u(i, t-1))
$$

Where Scost (i) is the cost of implementation of unit $i^{\text {th }}$ and $u(i, t)$ is the binary variable shows the on or off situation. The problem equal criteria are power balance and load distribution equations, showed in relations 8 and 9 .

$$
\begin{aligned}
P_{k}^{G}-P_{k}^{L} & =\sum_{i=1}^{N} V_{k} V_{i}\left[G_{k i} \cos \left(\theta_{k}-\theta_{i}\right)+B_{k i} \sin \left(\theta_{k}-\theta_{i}\right)\right] \\
Q_{k}^{G}-Q_{k}^{L} & =\sum_{i=1}^{N} V_{k} V_{i}\left[G_{k i} \sin \left(\theta_{k}-\theta_{i}\right)+B_{k i} \cos \left(\theta_{k}-\theta_{i}\right)\right]
\end{aligned}
$$

Inequality criteria contains the unit production, control variables, line transmission power and voltage limitations expressed in relations 10 to 13 .

$$
\begin{aligned}
P^{\min } & \leq P \leq P^{\max } \\
U^{\min } & \leq U \leq U^{\max } \\
\left|F_{i j}\right| & \leq F_{i j}^{\max } \\
V_{j}^{\min } & \leq V_{j} \leq V_{j}^{\max }
\end{aligned}
$$

It is obvious that if the load replacement time was given, the presented optimization problem can be formulated in OPF form (Wood et al, 2010). Therefore the GA and OPF algorithms have been used for the problem solvation. 


\section{Suggested Hybrid Algorithm}

In suggested algorithm a conjugation of OPF and GA methods has been utilized for the solvation of optimized extraction problem from micro nets via the demand side management.

The genetic strings conatin the replacement amount of each load per hur. Figure 1 shows a sample of genetic string for the suggested problem. It has $\mathrm{m}$ unit that is the managable loads. In each unit the 0 to 24 that show the replacement amount per hour. Figure 2 shows the suggested algorithm flowchart.

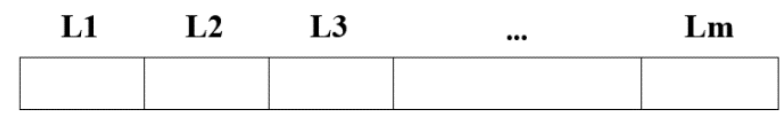

Fig1. Genetic strings in suggested hybrid algorithm

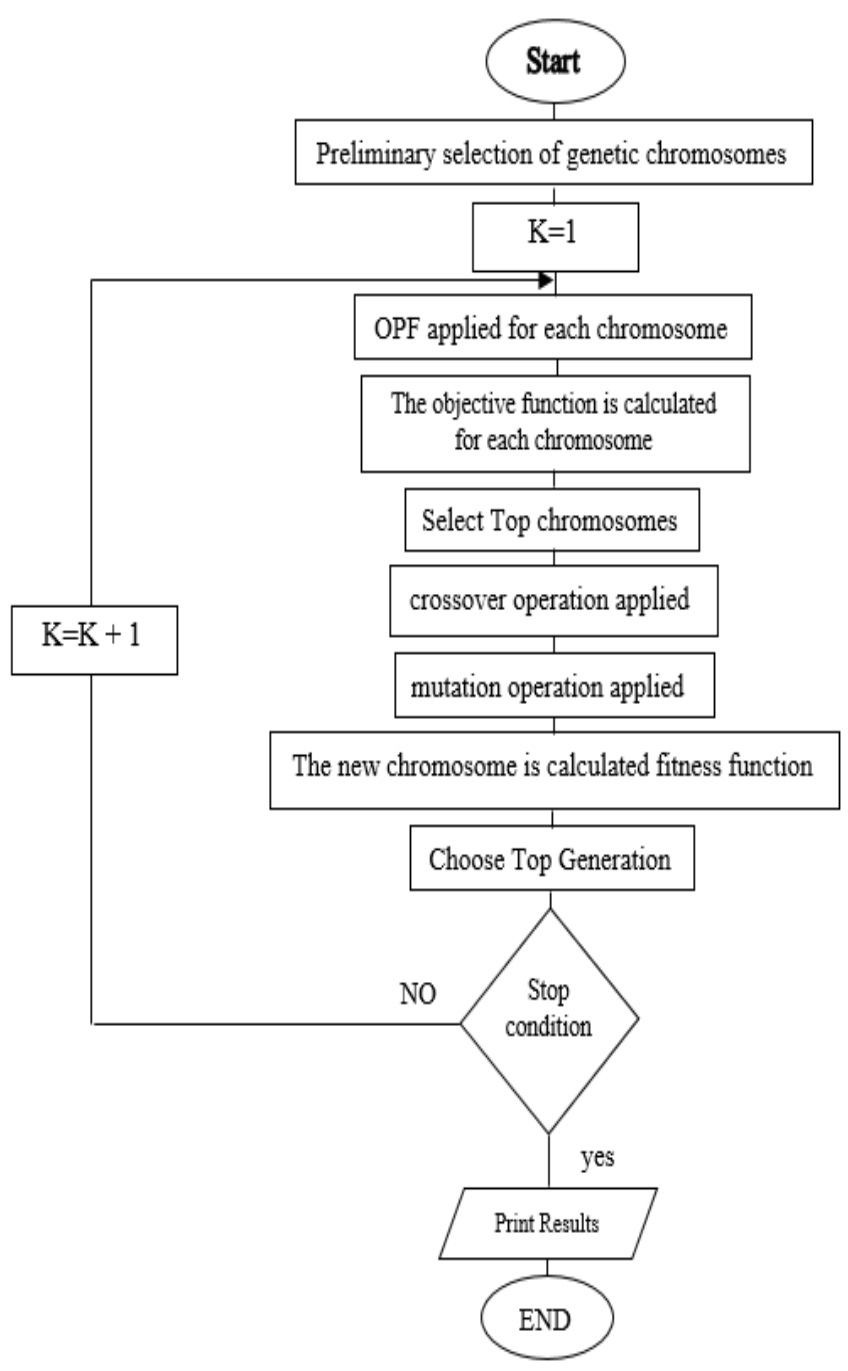

Fig2. Suggested hybrid algorithm flowchart

In this algorithm, at first initial guesses determined randomly for the load replacement per hour. Then the replacement time of each load is determined via the definite genetic strings. Solving the OPF problem the optimum amount of units is calculated and objective function is obtained for the initial strings which is the fitness function. Then the strings with higher value are selected using the genetic algorithm operators. The algorithm stops when the answer doesn't change despite of huge amount of itteration. The W1 and W2 weghit coefficients have been considered for different part of objective function.

\section{Numerical Results}

A micro net sample used in this article has been shown in figure 3 which connected at point PCC to the main network. 


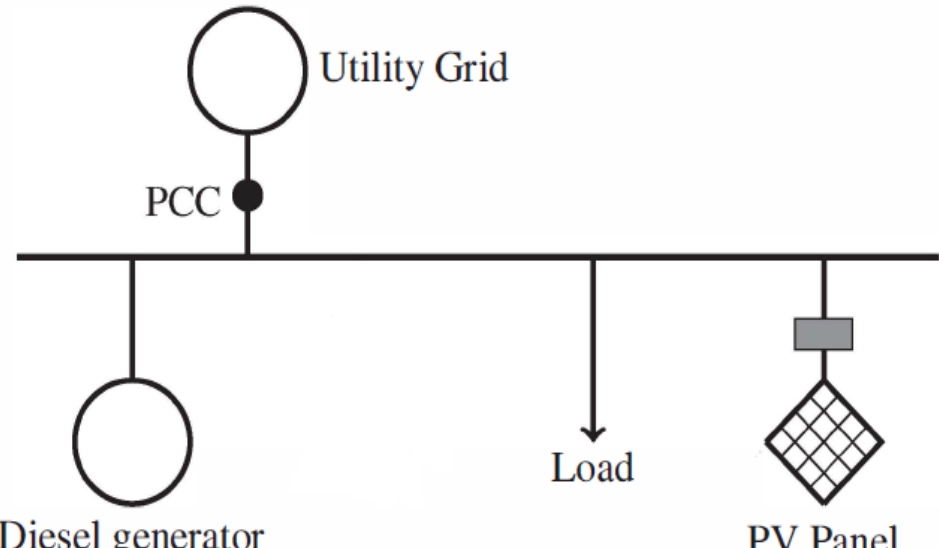

Fig3. Sample micro net

Generator diesel information of micro net is expressed in table 1.

table1. Generator diesel information

\begin{tabular}{|l|l|l|l|}
\hline Diesel Generator & $\mathbf{P}(\mathbf{m a x})$ & $\mathbf{P}(\mathbf{m i n})$ & Cost Function \\
\hline Microgrid & $4 \mathrm{MW}$ & $0.1 \mathrm{MW}$ & $\mathrm{F}(\mathrm{p})=22680 \mathrm{p}^{2}+15060 \mathrm{p}+817.47$ \\
\hline
\end{tabular}

In table 2 the solar plate producing power based on MW has been expressed

Table2. The solar plate producing power

\begin{tabular}{|l|l|l|l|}
\hline Time (hours) & PV(MW) & Time (hours) & PV(MW) \\
\hline 0 & 0 & 12 & 6.5208 \\
\hline 1 & 0 & 13 & 4.0560 \\
\hline 2 & 0 & 14 & 3.7674 \\
\hline 3 & 0 & 15 & 5.1636 \\
\hline 4 & 0 & 16 & 3.7128 \\
\hline 5 & 0 & 17 & 1.9890 \\
\hline 6 & 0 & 18 & 2.9640 \\
\hline 7 & 0 & 19 & 0 \\
\hline 8 & 1.1076 & 20 & 0 \\
\hline 9 & 2.6988 & 21 & 0 \\
\hline 10 & 4.0014 & 22 & 0 \\
\hline 11 & 5.8266 & 23 & 0 \\
\hline
\end{tabular}

In table 3 the energy sale and purchase price during 24 hours based on dollar. If the prices be constant, the energy sale price to network will be $40 \$$ per hour and the purchase price is $60 \$$ per hour.

Table3. The sale and purchase price of energy per dollar on hour

\begin{tabular}{|l|l|l|l|l|l|}
\hline Time (h) & Purchase Price & Sale Price & Time (h) & Purchase Price & Sale Price \\
\hline 0 & 56 & 44 & 12 & 57.2 & 45.2 \\
\hline 1 & 54.8 & 42.8 & 13 & 59 & 47 \\
\hline 2 & 59 & 47 & 14 & 60.2 & 48.2 \\
\hline 3 & 59.6 & 47.6 & 15 & 61.4 & 49.4 \\
\hline 4 & 60.8 & 48.8 & 16 & 63.2 & 51.2 \\
\hline 5 & 59.6 & 47.6 & 17 & 65 & 53 \\
\hline 6 & 59 & 47 & 18 & 68 & 56 \\
\hline 7 & 57.8 & 45.8 & 19 & 74 & 62 \\
\hline 8 & 57.2 & 45.2 & 20 & 68 & 56 \\
\hline 9 & 57.2 & 45.2 & 21 & 65.6 & 53.6 \\
\hline 10 & 59 & 44 & 22 & 61.4 & 49.4 \\
\hline 11 & 57.2 & 45.2 & 23 & 61 & 47 \\
\hline
\end{tabular}

Table 4 shows the load information based on MW during 24 hours. 
Optimum Extraction Of Micro Grid, Using The Load Transmission From The Demand Side...

Table4. Load information

\begin{tabular}{|c|c|c|c|c|c|c|c|c|c|c|c|}
\hline \multirow{2}{*}{$\begin{array}{l}\text { Time } \\
\text { (h) }\end{array}$} & \multirow{2}{*}{$\begin{array}{l}\text { Critical } \\
\text { Load }\end{array}$} & \multicolumn{10}{|c|}{ Removable load } \\
\hline & & L 1 & L 2 & L 3 & L 4 & L 5 & L 6 & L 7 & L 8 & L 9 & L 10 \\
\hline 0 & 2.559 & 0 & 0 & 0.050 & 0 & 0 & 0 & 0 & 0.300 & 0 & 0 \\
\hline 1 & 2.526 & 0 & 0 & 0.050 & 0 & 0 & 0 & 0 & 0.600 & 0 & 0 \\
\hline 2 & 2.526 & 0 & 0 & 0.050 & 0 & 0 & 0 & 0 & 1.200 & 0 & 0 \\
\hline 3 & 2.583 & 0 & 0 & 0.100 & 0.400 & 0 & 0 & 0 & 1.200 & 0 & 0 \\
\hline 4 & 2.555 & 0 & 0 & 0.100 & 0.400 & 0 & 0 & 0 & 1.200 & 0 & 0 \\
\hline 5 & 2.735 & 0 & 0 & 0.050 & 0.400 & 0 & 0 & 0 & 0.700 & 0 & 0 \\
\hline 6 & 2.956 & 0.100 & 0 & 0 & 0.400 & 0 & 0 & 0 & 0.500 & 0 & 0 \\
\hline 7 & 3.050 & 0.200 & 0 & 0 & 0.300 & 0 & 0.600 & 0 & 0.200 & 0.900 & 0 \\
\hline 8 & 3.012 & 0.500 & 0 & 0 & 0.300 & 0 & 0.650 & 0 & 0 & 1.000 & 0 \\
\hline 9 & 3.106 & 0.500 & 0.100 & 0 & 0.300 & 0 & 0.650 & 0 & 0 & 1.000 & 0.100 \\
\hline 10 & 3.009 & 0.500 & 0.100 & 0 & 0.300 & 0 & 0.600 & 0 & 0 & 1.000 & 0.200 \\
\hline 11 & 3.010 & 0.200 & 0.100 & 0 & 0 & 0 & 0.600 & 0 & 0 & 1.000 & 0.200 \\
\hline 12 & 2.956 & 0.100 & 0.100 & 0 & 0 & 0 & 0 & 0 & 0 & 1.200 & 0.200 \\
\hline 13 & 3.037 & 0 & 0.100 & 0 & 0 & 0 & 0 & 0.200 & 0 & 1.000 & 0.200 \\
\hline 14 & 2.922 & 0 & 0 & 0 & 0 & 0 & 0 & 0.300 & 0 & 0.800 & 0.200 \\
\hline 15 & 3.006 & 0 & 0 & 0 & 0 & 0.200 & 0 & 0.500 & 0 & 0 & 0.200 \\
\hline 16 & 3.035 & 0 & 0 & 0 & 0 & 0.200 & 0 & 0.700 & 0 & 0 & 0.200 \\
\hline 17 & 3.132 & 0 & 0 & 0 & 0 & 0.200 & 0 & 0.900 & 0 & 0 & 0.200 \\
\hline 18 & 3.161 & 0 & 0 & 0 & 0 & 0.300 & 0 & 0.900 & 0 & 0 & 0.100 \\
\hline 19 & 2.996 & 0 & 0 & 0 & 0 & 0.300 & 0 & 0.900 & 0 & 0 & 0.100 \\
\hline 20 & 2.996 & 0 & 0 & 0 & 0 & 0 & 0 & 0.500 & 0 & 0 & 0 \\
\hline 21 & 2.813 & 0 & 0 & 0 & 0 & 0 & 0 & 0.200 & 0 & 0 & 0 \\
\hline 22 & 2.703 & 0 & 0 & 0 & 0 & 0 & 0 & 0.100 & 0 & 0 & 0 \\
\hline 23 & 2.631 & 0 & 0 & 0 & 0 & 0 & 0 & 0 & 0 & 0 & 0 \\
\hline
\end{tabular}

In table 5 the cost function coefficient for demand side management program performance.

Table5. Cost function coefficient of demand side management

\begin{tabular}{|r|r|r|r|r|r|r|r|}
\hline Kind of load & A & B & C & Kind of load & A & B & C \\
\hline L 1 & 0 & 230 & 1000 & L 6 & 0 & 110 & 4000 \\
\hline L 2 & 0 & 530 & 2000 & L 7 & 20 & 330 & 5000 \\
\hline L 3 & 0 & 610 & 1000 & L 8 & 0 & 250 & 3000 \\
\hline L 4 & 32 & 960 & 5000 & L 9 & 0 & 160 & 2000 \\
\hline L 5 & 0 & 520 & 3000 & L 10 & 0 & 480 & 3000 \\
\hline
\end{tabular}

\section{Suggested algorithm performance}

In this section the suggested algorithm has been performed on sample net. For this aim the W1 and W2 weight coefficeint equal to 1 and the energy sale and purchase prices have been considered variable. The population number is 500 and the itteration number is 200 . In figure 4 the GA algorithm convergence has been shown.

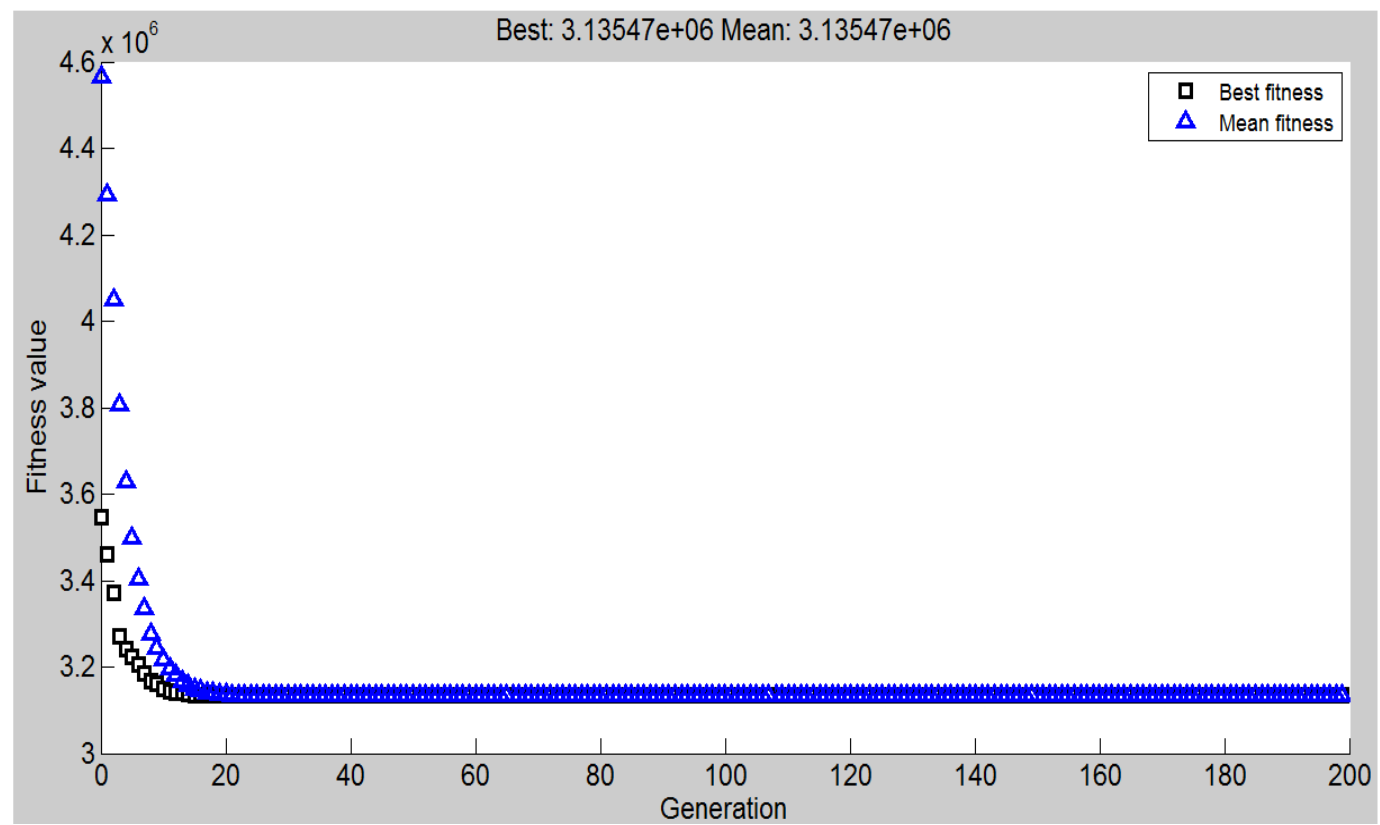

Fig4. Convergence of optimization problem 
The results have been expressed in tables 6 and 7 in table 6 the replacement amount for each time and the CF and DC have been shown. In table 7 the amount of unit productions and received power based on MW.

Table6. Replacement amount of costs and loads

\begin{tabular}{|c|c|c|c|c|c|c|c|c|c|c|c|c|c|}
\hline \multicolumn{10}{|c|}{ Load shift time (hours) } & \multicolumn{2}{|l|}{ Cost } & \multirow{2}{*}{$\begin{array}{l} \\
2 \\
\end{array}$} & \multirow{2}{*}{$\begin{array}{c}\text { W } \\
\mathbf{1}\end{array}$} \\
\hline ST1 & ST2 & ST3 & ST4 & ST5 & ST6 & ST7 & ST8 & ST9 & ST10 & $\mathrm{DC}(\$ / \mathbf{h})$ & $\mathbf{C F}(\$ / \mathbf{h})$ & & \\
\hline 3 & 0 & 1 & 0 & 0 & 1 & 0 & 8 & 2 & 0 & 53820 & 3081652.3354 & 1 & 1 \\
\hline
\end{tabular}

Table7. Unit produced power and received power from net

\begin{tabular}{|l|l|l|l|l|l|}
\hline $\begin{array}{l}\text { Time } \\
(\mathbf{h})\end{array}$ & $\begin{array}{l}\text { Power Main } \\
\text { Grid (MW) }\end{array}$ & $\begin{array}{l}\text { grid Power Micro } \\
\text { (MW) }\end{array}$ & $\begin{array}{l}\text { Time } \\
\text { (h) }\end{array}$ & $\begin{array}{l}\text { Power Main } \\
\text { Grid (MW) }\end{array}$ & $\begin{array}{l}\text { Power Micro grid } \\
(\mathbf{M W})\end{array}$ \\
\hline 0 & 1.66 & 0.90 & 12 & 0.036 & 0 \\
\hline 1 & 1.70 & 0.88 & 13 & 0.71 & 0.97 \\
\hline 2 & 1.61 & 0.97 & 14 & 0.56 & 1.00 \\
\hline 3 & 2.05 & 0.98 & 15 & 0 & 0.44 \\
\hline 4 & 2.05 & 1.01 & 16 & 0.16 & 1.06 \\
\hline 5 & 2.25 & 0.98 & 17 & 1.34 & 1.10 \\
\hline 6 & 2.44 & 0.97 & 18 & 0.33 & 1.17 \\
\hline 7 & 2.41 & 0.94 & 19 & 3.00 & 1.30 \\
\hline 8 & 2.18 & 0.93 & 20 & 2.33 & 1.17 \\
\hline 9 & 2.23 & 0.93 & 21 & 1.90 & 1.11 \\
\hline 10 & 1.69 & 0.97 & 22 & 1.78 & 1.02 \\
\hline 11 & 0 & 0.78 & 23 & 1.62 & 1.01 \\
\hline
\end{tabular}

\section{Sensitivity Analysis}

In this part the effect of weight coefficient, solar plates and the energy price on extraction and demand side management costs have been evaluated and the results have been analyzed.

\section{Weight coefficient effect}

The effect of weight coefficient has been shown in table 8 .

Table8. Weight coefficient effect

\begin{tabular}{|c|c|c|c|c|c|c|c|c|c|c|c|c|c|}
\hline \multicolumn{10}{|c|}{ Load shift time (hours) } & & Cost & \multirow{3}{*}{ W2 } & \multirow{3}{*}{ W1 } \\
\hline ST & ST & ST & ST & ST & ST & ST & ST & ST & ST & & & & \\
\hline 1 & 2 & 3 & 4 & 5 & 6 & 7 & 8 & 9 & 10 & $\mathrm{DC}(\$ / \mathrm{h})$ & $\mathrm{CF}(\$ / \mathrm{h})$ & & \\
\hline 6 & 0 & 5 & 6 & 17 & 4 & 17 & 9 & 2 & 23 & 0 & 3016445.0043 & 0 & 1 \\
\hline 3 & 0 & 0 & 0 & 0 & 1 & 0 & 8 & 2 & 0 & 53820 & 3081652.3354 & 1 & 1 \\
\hline 0 & 1 & 0 & 0 & 1 & 0 & 0 & 1 & 0 & 0 & 18600 & 3174678.1628 & 2 & 1 \\
\hline- & - & - & - & - & - & - & - & - & & - & 3144023.2700 & Withot & DSM \\
\hline
\end{tabular}

W1, W2, CF, DC are the extraction cost weight coefficient, cost of demand side management programs, extraction costs and cost of demand side management programs based on dollar per hour. ST1 to ST10 are the load replacement of kind 1 to kind 10. The extraction cost assumed constant and equal to 1 while the costs of demand side management programs increases.

\section{Solar plate effect}

At first the optimization problem solved in presence of solar plates and then they were eliminated and the problem solved again. After the load replacement amount in each state, the extraction and demand side management programms costs have been calculated and presented in table 9 .

Table9. Solar plate effect

\begin{tabular}{|c|c|c|c|c|c|c|c|c|c|c|c|c|}
\hline \multicolumn{10}{|c|}{ Load shift time (hours) } & \multicolumn{2}{|l|}{ Cost } & \multirow[b]{2}{*}{ PV } \\
\hline $\begin{array}{l}\text { ST } \\
1\end{array}$ & $\begin{array}{l}\text { ST } \\
2\end{array}$ & $\begin{array}{l}\text { ST } \\
3\end{array}$ & $\begin{array}{l}\text { ST } \\
4\end{array}$ & $\begin{array}{l}\text { ST } \\
5\end{array}$ & $\begin{array}{l}\text { ST } \\
6\end{array}$ & $\begin{array}{l}\text { ST } \\
7\end{array}$ & $\begin{array}{l}\text { ST } \\
8\end{array}$ & $\begin{array}{l}\text { ST } \\
9\end{array}$ & $\begin{array}{l}\text { ST } \\
10\end{array}$ & DC $(\$ / h)$ & CF $(\$ / h)$ & \\
\hline 3 & 0 & 0 & 0 & 0 & 1 & 0 & 8 & 2 & 0 & 53820 & 3081652.3354 & Active \\
\hline 1 & 1 & 1 & 0 & 0 & 0 & 1 & 4 & 0 & 0 & 26720 & 5556267.2400 & Inactive \\
\hline
\end{tabular}

Table 9 shows that with solar plate elimination the load replacement and demand side management costs have been decreased but the extraction costs increases highly.

\section{Energy price effect}

At first the optimization problem solved with sale and purchase prices of energy variety, then the prices considered constant and after that the problem has been solved and results have been shown in table 10 . The 
variable prices have been obtained from table 4 . If the prices was constant, the energy purchase and sale price of network have been considered 60 and $40 \$$ respectively.

Table10. Energy price effect

\begin{tabular}{|l|l|l|l|l|l|l|l|l|l|l|l|l|}
\hline \multicolumn{1}{|l|}{ Load shift time (hours) } & Cost & Price \\
\hline ST & ST & ST & ST & ST & ST & ST & ST & ST & ST & DC(\$/h) & CF(\$/h) & \\
1 & 2 & 3 & 4 & 5 & 6 & 7 & 8 & 9 & 10 & & \\
\hline 3 & 0 & 0 & 0 & 0 & 1 & 0 & 8 & 2 & 0 & 53820 & 3081652.3354 & Variable \\
\hline 3 & 1 & 1 & 0 & 0 & 1 & 0 & 8 & 3 & 1 & 64240 & 3026958.2900 & constant \\
\hline
\end{tabular}

The load replacement has been increased with constant prices and therefore the performance cost of demand side management increases consequently but the extraction cost has been decreased.

\section{Conclusion}

In this article the optimized extraction of micro net along with demand side management programs has been modelled. Objective function of this problem is the minimizing of costs consists of extraction, demand side management and the costs of demand side management programs for the customer displeasure reduction. The hybrid GA and OPF algorithm has been used for the optimization problem solving. All limitations have been considered in load distribution program. Only the answer convergence and load replacement limitations are located in GA during the 24 hours. The results have shown that reaching to the least cost, the demand side management should be considered in addition to extraction costs. Although the demand side management has costs but during the study period reduced the total costs of systems.

\section{Refernces}

[1]. Ching Liao G, Ian Tsai J ,( 2012) "Use A New Method to Solve the Economic Dispatch Problem of Smart MicroGrid Including Distributed Generation”, IEEE, Power and energy engineering conference, Shanghai, 1-4 .

[2]. Z Hu, X Han, Q Wen ,(2013) Integrated Resource Strategic Planning and Power Demand-Side Management ,China Electric Power Press and speringer, 63-133.

[3]. Jayadev V , Swarap K S ,(2013) “ Optimization of Microgrid with Demand Side Management using Genetic Algorithm” , IET conference on power in unity a whole system, London ,1-6.

[4]. Keyhani A, Marwali M , (2011) Smart Power Grids . USA Springer, 1-81

[5]. H Liu , Y Wu , C Qian , X Liu , (2012) "The Application of Dynamic Programming in the Stand-alone Micro-grid Optimal Operation" IEEE, Power and energy engineering conference, Shanghai, 1-5.

[6]. Toma 1, Bica D , (2013) “Economic operation of distributed energy resources in a microgrid” IEEE, Power tech, Grenoble ,1-5

[7]. Wood A J , Wollenberg B F, Sheble G B , (2010) Power Generation, Operation and control, 2nd ed, Wiley Interscience publication , 514-555 